\title{
AS CRIANÇAS COMO PESQUISADORAS: OS EFEITOS DOS DIREITOS DE PARTICIPAÇÃO SOBRE A METODOLOGIA DE PESQUISA*
}

\author{
Priscilla Alderson ${ }^{* *}$
}

\begin{abstract}
RESUMO: Este artigo contempla questôes que surgem para os adultos que fazem pesquisa com crianças pesquisadoras. Esses pontos são ilustrados mais por meio de uma revisão da literatura internacional do que por um relatório de pesquisa original. Três áreas principais serão abordadas: os estágios do processo de pesquisa em que as crianças podem ser envolvidas como atores; os níveis de participação das crianças; e o uso de métodos que podem aumentar o envolvimento informado das crianças em pesquisas, sem deixar de respeitar seus direitos. Considero as crianças co-produtoras de dados durante as pesquisas realizadas com elas.
\end{abstract}

Palavras-chave: Crianças. Jovens. Métodos de pesquisa. Participação.

\section{CHILDREN AS RESEARCHERS:}

THE EFFECTS OF PARTICIPATION RIGHTS ON RESEARCH METHODOLOGY

ABSTRACT: This paper considers issues raised for adults who do research with child researchers. The points will be illustrated through a review of an international literature rather than an original research report. Three main areas will be discussed: stages of the research process at which children can be involved as actors; levels of children's participation; and the use of methods which can increase children's

Este artigo foi originalmente publicado em Christensen (Ed.), Research with children: perspectives and practices, Falmer Press/Routledge, 2000, p. 241-255. Agradeço a todos os jovens que me ajudaram a fazer pesquisa, ao ESRC Children 5-16 Programme (Programa para Crianças de 5 a 16 anos do ESRC) por financiar nossa pesquisa sobre direitos civis em escolas, a qual, de modo indireto, contribuiu para este artigo, e a todos que contribuíram com muito mais exemplos de pesquisa por crianças que não pude incluir aqui.

Tradução de Alain François, com revisão técnica de Fernanda Müller.

** Professora de estudos da infância da Social Science Research Unit, Institute of Education, Universidade de Londres. E-mail: p.alderson@ioe.ac.uk

Educ. Soc., Campinas, vol. 26, n. 91, p. 419-442, Maio/Ago. 2005

Disponível em <http://www.cedes.unicamp.br> 
As crianças como pesquisadoras: os efeitos dos direitos de participação...

informed involvement in research, thereby respecting their rights. The idea of seeing the 'researched' adult as a co-researcher or co-producer of data, and equally involved in the analysis, is already widely acknowledged. This idea is usually argued for in terms of control, and of addressing power imbalances in the research relationship. It can also be justified in terms of efficiency, as opening the way to a broader range of collection methods and fuller understanding of the data. This paper, similarly, sees children as co-producers of data during research conducted with them.

Key words: Children. Young people. Research methods. Participation.

\section{Introdução}

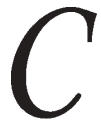

ada vez mais crianças estão sendo envolvidas como pesquisadoras. Este artigo contempla questóes que surgem para os adultos que fazem pesquisa com crianças pesquisadoras. Esses pontos serão ilustrados mais por meio de uma revisão da literatura internacional do que por um relatório de pesquisa original. Três áreas principais serão discutidas: os estágios do processo de pesquisa em que as crianças podem se envolver como atores; os níveis de participação das crianças; e o uso de métodos que podem aumentar o envolvimento informado das crianças em pesquisa, sem deixar de respeitar seus direitos. A idéia de ver os adultos "pesquisados" como co-pesquisadores ou co-produtores dos dados, e como envolvidos na análise, já é amplamente reconhecida. Essa idéia é geralmente defendida em termos de controle e para resolver desequilíbrios de poder na relação de pesquisa. Contudo, ela também pode se justificar em termos de eficácia, pois oferece um leque mais amplo de métodos de coleta e permite uma compreensão mais plena dos dados. Do mesmo modo, este artigo vê as crianças como coprodutoras de dados durante as pesquisas realizadas com elas.

Um tema explícito e implícito dentro desse tipo de co-pesquisa é o respeito pelo grupo pesquisado e pelas suas próprias visóes e habilidades. Ora, o respeito está estreitamente relacionado com os direitos, e as convenções de direitos oferecem meios com princípios, embora flexíveis, de justificar e estender as práticas respeitosas (Spencer, 1998). Por terem um apoio quase universal e um status quase legal, as convenções de direitos fornecem, portanto, uma justificativa formal para respeitar padróes éticos em pesquisa. A consciência crescente dos direitos da cri- 
ança, e de outros grupos "minoritários", inclusive as mulheres, tem preparado o terreno para envolver crianças como pesquisadoras.

Internacionalmente, os direitos das crianças adquiriram uma nova dimensão na última década com os assim chamados direitos de participação. Tradicionalmente, as crianças sempre foram excluídas do que é conhecido como a primeira geração de direitos, ou direitos à autonomia: proteção contra as interferências e direitos à integridade física e mental e à autodeterminação. Eram consideradas estando sob a proteção e o controle de seus pais. Inicialmente preocupadas com as vítimas de guerra, as declarações internacionais dos direitos da criança enfatizaram sua necessidade de proteção contra o menosprezo e os abusos e de receberem bens e serviços. Até recentemente, as pesquisas sobre crianças refletiam essas prioridades e costumavam medir os efeitos das intervenções de saúde ou educação sobre suas vidas, ou suas necessidades, tais como avaliadas por adultos, ou ainda investigavam seu desenvolvimento e sua socialização graduais rumo às competências dos adultos.

Contudo, a nova dimensão dos direitos de participação das crianças, inscrita na Convenção da ONU sobre os Direitos da Criança (ONU, 1989), envolve versões moderadas dos direitos de autonomia dos adultos. Elas dizem respeito a crianças que tomam parte em atividades e decisōes que as afetam. Os direitos de participação incluem mais particularmente três dos 54 artigos da Convenção. Os Estados deveriam garantir:

à criança que for capaz de formular seus próprios juízos o direito de expressar suas opiniōes livremente sobre todos os assuntos relacionados à criança, levando-se devidamente em consideração essas opiniōes, em função da idade e maturidade da criança. (12); ${ }^{*}$

(...) o direito à liberdade de expressão. Esse direito incluirá a liberdade de procurar, receber e divulgar informaçóes e idéias de todo tipo (...) por meio das artes ou por qualquer outro meio escolhido pela criança (...) (13);

(...) o direito da criança ao descanso e ao lazer, ao divertimento e às atividades recreativas próprias da idade, bem como à livre participação na vida cultural e artística. (31).

N. do T.: Os números entre parênteses correspondem ao número do artigo da Convenção. As traduções da Convenção foram extraídas do site: <http://www.onu-brasil.org.br/ doc_crianca.php>.

Educ. Soc., Campinas, vol. 26, n. 91, p. 419-442, Maio/Ago. 2005 
As crianças como pesquisadoras: os efeitos dos direitos de participação...

Nessa Convenção os direitos são qualificados de modos importantes. Alguns são aspirações, por exemplo, ainda não plenamente realizáveis, que "cada nação adotará (...) utilizando ao máximo os recursos disponíveis" (4). Os direitos também não são absolutos, mas condicionais, afetados pelas "capacidades em desenvolvimento da criança" e pelas "responsabilidades, os direitos e os deveres dos pais" (5) e pela lei nacional. "A consideração primordial deve ser o interesse maior da criança” $(1,21)$. Os Direitos da Criança não podem ser exercidos de maneiras que possam ferir a criança ou outras pessoas. Eles devem "respeitar os direitos e a reputação dos demais", assim como a "segurança nacional, e a ordem, a saúde e a moral públicas” (13). Esses direitos não dizem respeito a um individualismo egoísta, mas à solidariedade, à justiça social e a uma distribuição justa. Reivindicar um direito significa reconhecê-lo a todos. A reivindicação afirma o valor e a dignidade de cada pessoa. $\mathrm{O}$ respeito dos Direitos da Criança promove "o progresso social e a elevação do nível de vida com mais liberdade” (Preâmbulo da Convenção).

Todos os governos, exceto o dos Estados Unidos e o da Somália, ratificaram a Convenção, e comprometeram-se a torná-la conhecida "tanto para os adultos como para as crianças", a ela conformar as leis e os serviços dos Estados, e a relatar regularmente à ONU os progressos nestes pontos. Entretanto, esses Direitos da Criança geram controvérsias, pois os direitos de participação podem tanto complementar como entrar em conflito com os direitos à provisão e proteção (Alderson \& Goodwin, 1993).

Nessas controvérsias, vários pontos alteraram o estatuto das crianças nas pesquisas e como pesquisadoras, durante os anos de 1990, por exemplo: as conseqüências da sentença do caso Gillick, em 1985, que reconheceu que crianças com menos de 16 anos podem dar um consentimento válido (para mais informações, ver Alderson \& Montgomery, 1996); o novo respeito, na sociologia da infância, para as crianças na qualidade de atores sociais competentes, e não mais como simplesmente subsumidas em categorias dominadas pelos adultos, como a família (Qvortrup et al., 1994; James \& Prout, 1997); a tão propalada eloqüência das crianças jovens, por exemplo, na televisão. Uma questão importante para este artigo é que também existem pesquisas feitas pelas próprias crianças, as quais vêm sendo amplamente patrocinadas por organizações não-governamentais (ONGs) e respeitam a Convenção da ONU. É delas que trataremos. 
Questôes que os direitos da criança geram para pesquisadores adultos

A participação das crianças envolve uma mudança na ênfase dos métodos e assuntos de pesquisa. Reconhecer as crianças como sujeitos em vez de objetos de pesquisa acarreta aceitar que elas podem "falar" em seu próprio direito e relatar visōes e experiências válidas. Essas "falas" podem envolver língua de sinais, quando as crianças não podem ouvir ou falar, e outros sons e linguagens corporais expressivas, tais como os das crianças autistas ou com graves dificuldades de aprendizagem (Alderson \& Goodey, 1998). Logo, envolver todas as crianças mais diretamente nas pesquisas pode resgatá-las do silêncio e da exclusão, e do fato de serem representadas, implicitamente, como objetos passivos, ao mesmo tempo em que o respeito por seu consentimento informado e voluntário ajuda a protegê-las de pesquisas encobertas, invasivas, exploradoras ou abusivas.

Este último ponto é importante, pois um dos maiores obstáculos, ao se fazer pesquisas com crianças, é infantilizá-las, percebê-las e tratá-las como imaturas e, com isso, produzir provas que apenas reforçam as idéias sobre sua incompetência. Isso pode incluir "falar com condescendência", usar palavras e conceitos simples demais, restringilas a dar apenas respostas superficiais, e envolver apenas crianças inexperientes e não as que têm experiências relevantes intensas e poderiam dar respostas muito mais informadas. Por exemplo, as visōes das crianças sobre patologia e tratamentos médicos costumam ser coletadas de amostras médias de crianças principalmente saudáveis (Wilkinson, 1988). Elas parecem ser relativamente ignorantes, apesar das informaçôes que podem conseguir pela televisão ou por outras fontes. Em contrapartida, as crianças que sofrem de doenças crônicas terão um conhecimento muito mais amplo sobre a natureza e o objetivo dos tratamentos médicos; crianças de 2 anos com câncer podem falar com tanta compreensão que desafiam as crenças sobre sua incapacidade de entender (Kendrick, 1986).

Além disso, os termos, assuntos e métodos complicados demais ou muito mal explicados pelos pesquisadores também podem, de modo errôneo, fazer com que as crianças (e alguns adultos) pareçam ser ignorantes ou incapazes. Entretanto, as crianças podem ajudar os pesquisadores adultos a adotarem níveis de fala mais apropriados (Solberg, 1997; O'Kane, 2000). Durante uma pesquisa sobre o con- 
As crianças como pesquisadoras: os efeitos dos direitos de participação...

sentimento das crianças para cirurgias, perguntei a uma criança de 10 anos: "Então, vão fazer suas pernas crescerem?" e ela respondeu: "Tenho acondroplasia e eles vão alongar os meus fêmures”, mostrando-me, educadamente, seu sofisticado nível de fala e percepção (Alderson, 1993).

Outro obstáculo para as crianças é o pressuposto, comum aos adultos, de que o consentimento dos pais ou professores basta, e que as crianças não precisam ou não podem exprimir seu próprio consentimento ou recusa a participar de pesquisas. A própria British Education Research Association ${ }^{1}$ (BERA, 1992) nem mesmo menciona o consentimento das crianças em suas diretrizes éticas. Portanto, a pesquisa social pode contribuir para o extenso debate sobre o consentimento das crianças (para uma análise, ver Alderson, 1995), ao fornecer provas da competência das crianças em sua vida cotidiana e em pesquisas (por exemplo, em Hutchby \& Moran-Ellis, 1998). Na sociologia da infância, é muito comum, hoje em dia, afirmar que as crianças são e devem ser vistas como atores na construção social e na determinação de suas próprias vidas, das vidas dos que as cercam e de sua sociedade. Logo, surgem duas questóes relacionadas. Primeiro, se as relaçóes sociais e a cultura das crianças em si merecem estudo, então quem é mais qualificado para pesquisar alguns aspectos de suas vidas do que as próprias crianças? (James \& Prout, 1997). Segundo, se crianças podem ser participantes ativos, como este artigo afirma, também podem ser pesquisadores ativos?

\section{Crianças como pesquisadores}

Uma primeira maneira de as crianças serem pesquisadores são os projetos cotidianos que fazem na escola. Nas escolas que visitei, por exemplo, Adam, de 5 anos, montou um gráfico com os bichinhos de estimação que as crianças de sua turma possuíam, e Helen, de 16 anos, gravou entrevistas com seus amigos a respeito dos divórcios de seus pais para seu muito bem avaliado projeto de psicologia. O projeto de fim de ensino médio (GCSE) em geografia de Tariq tratava dos loteamentos locais ameaçados de serem fechados e levou-o a pesquisar os cadastros da prefeitura e a assistir a reuniões do Conselho Municipal. Turmas de crianças entre 9 e 11 anos assistiram a um vídeo sobre lagos, e organizaram uma sessão de exibição de idéias e discussões em pequenos gru- 
pos para planejar e desenhar um lago para o pátio de sua escola. Calcularam um orçamento e, com a ajuda de adultos, criaram e povoaram o lago.

Nestes exemplos, aprender, a ocupação principal de todos na escola, sobrepõe-se à pesquisa, mas esta rica produção de pesquisa das escolas britânicas quase nunca é publicada, e tende a ser vista como "exercícios" em vez de valer a pena em si. Em contraste, atividades comparáveis podem ser altamente valorizadas em outras sociedades, o que nosso próximo exemplo confirma. Muitas crianças ugandenses formam a primeira geração que vai à escola e se tornaram educadores em pesquisa e saúde para a comunidade. Graças ao Child-to-Child Trust, ${ }^{2}$ que promove a educação pelos pares, as 600 crianças da escola primária de uma aldeia mostraram-se preocupadas com o fato de os animais usarem o reservatório de água principal. As crianças falaram com o líder da aldeia, que convocou uma reunião na qual as crianças apresentaram poesias e dramas a respeito do valor da água limpa. Como resultado, crianças e adultos trabalharam juntos para limpar o lago e construíram uma cerca para impedir a aproximação dos animais (ISCA, 1995, p. 236).

A segunda maneira mais comum de as crianças serem envolvidas em pesquisa são os projetos criados e conduzidos por adultos (ver O'Kane, 2000; Davis et al.; Roberts; e Christensen \& James, 2000). Contudo, além de fornecerem dados em seu tradicional papel como sujeitos de pesquisas, as crianças ajudam cada vez mais a planejar perguntas e coletar, analisar ou relatar provas, ou tornar os resultados públicos. Por exemplo, a respeito de um conjunto habitacional particularmente sujeito a acidentes,

Os adolescentes tinham pouco a dizer a respeito dos tipos de eventos que nós [pesquisadores] considerávamos acidentes. Nem reagiam bem à noção de segurança ou salvaguarda. Finalmente, perguntamos qual deveria ser nossa primeira pergunta: "Perguntem sobre nossas cicatrizes", responderam. Fizemos isso e conseguimos informaçôes significativas e detalhadas sobre um certo número de eventos de acidentes. (Roberts et al., 1995)

As respostas iniciais dos adolescentes poderiam facilmente ser usadas para confirmar os pressupostos sobre sua ignorância e incompetência. Em contraste, a abordagem em parceria ajudou a desenvolver novas teorias e métodos para pesquisa sobre acidentes e sua prevenção, e produziu conclusões, além de outros projetos com crianças menores. 
As crianças como pesquisadoras: os efeitos dos direitos de participação...

Realmente, as crianças são provavelmente mais interessadas que os adultos por cada estágio da pesquisa. Muitas delas estão acostumadas a questionar, investigar e aceitar resultados inesperados, mudar de idéia, e assumir que seus conhecimentos são incompletos e provisórios. Crianças de idade pré-escolar costumam fazer perguntas básicas sobre filosofia e método e em torno dos 5 anos já conseguiram compreensões que duram a vida inteira (Lipman, 1993; Tizzard \& Hughes; 1984; Gardner, 1993). Crianças muito jovens também podem participar de tomadas de decisões de grupo e concordar sobre prioridades (Miller, 1997). As crianças podem ter menos a perder e mais a ganhar, ao fazerem perguntas radicais como: Por que temos reunióes escolares? Os adultos, em compensação, podem se sentir ameaçados por pesquisas, pois podem questionar criticamente seus conhecimentos, autoridade ou conveniência.

A terceira maneira, menos comum embora em plena expansão, é a pesquisa iniciada e dirigida principalmente por crianças e adolescentes (West, 1997; PEG, 1998a, 1998b). Métodos para envolver adultos iletrados como pesquisadores, como as avaliações rurais participativas (Pratt \& Loizos, 1992), são também eficientemente usados com e por crianças (Johnson et al., 1996; O’Kane, 2000; e Christensen \& James, 2000). A próxima seção revisa os estágios, níveis e métodos nos quais as crianças são envolvidas como pesquisadores.

Estágios de pesquisa quando as crianças são envolvidas

Quando o objetivo principal é o de acrescentar conhecimento, as pesquisas em escolas e universidades tendem a se concentrar nos estágios intermediários: coletar e analisar dados e escrever relatórios. Em contraste, as pesquisas feitas por jovens, os quais se preocupam em obter mudanças, por exemplo, no acesso, nas oportunidades ou na maneira como serviços são prestados, também costumam enfatizar os primeiros e últimos estágios do processo de pesquisa. Os primeiros estágios incluem selecionar e organizar a equipe de pesquisa e os grupos da amostra, evitando a participação simbólica (tokenism), estabelecendo relações de equipe e de poder e maneiras de resolver problemas à medida que surgem, decidindo juntos a agenda, as metas, os métodos e os pagamentos em dinheiro ou em espécie (ver, por exemplo, Cockburn et al., 1997). Essas importantes decisóes iniciais costumam 
ser consideradas simples formalidades nos times de pesquisa profissionais hierárquicos. As crianças e os adolescentes também tendem a ser logo profundamente preocupados com os estágios de acompanhamento, bem como tornar públicos e usar os resultados de pesquisa para mudar o mundo. "Queremos mostrar isso aos trabalhadores sociais/às autoridades do planejamento/ao Ministério da Educação" podem ser metas iniciais explícitas (PEG, e Allan Siddall, comunicação pessoal). No fim dos anos de 1980, no Brasil, por exemplo, o movimento nacional de crianças de rua influenciou a redação de códigos legais que vão da nova Constituição Federal às leis municipais que integram os direitos das crianças, com base nas pesquisas que estas realizaram (SCF, 1995). Esses outros exemplos a seguir também ilustram como os jovens trabalham em vários estágios de pesquisa.

O Participation and Education Group ${ }^{3}$ (PEG, 1998a) pesquisou quão doentias as escolas podem ser. Os 187 jovens entre 5 e 25 anos que responderam às 14 perguntas associam claramente saúde física e mental: "Se não conseguir dar conta do recado, pegam no teu pé e te chamam de tapado. Você se sente mal, acabado". Esse animado relatório de pesquisa inclui gráficos, gráficos de pizza, poesias, citações e traz fortes recomendações. O PEG também fez apresentações teatrais sobre suas pesquisas para profissionais de saúde, e no Ministério da Educação e do Trabalho. As crianças usam métodos de oportunidades iguais promovidos em treinamento assertivo (assertion training) e por trabalhadores dos direitos (Treseder, 1997). Depois de breve formação, sua assertividade abala os pressupostos de que as crianças são inevitavelmente vulneráveis. Por exemplo, algumas das mais jovens estabeleceram a agenda e presidiram um encontro de jovens a partir de 8 anos com adultos, para planejar uma conferência. Prescreveram regras de escuta respeitosa, e os adultos eram educadamente convidados a não interromper nem falar às crianças sem condescendência. Todos tiveram sua vez para responder a perguntas como: Por que estamos tendo esse encontro? O que você ganhou com ele? (PEG, 1998b)

Em Camden, Londres, adolescentes originários de Bangladesh pesquisaram as necessidades de jogo e lazer de crianças de Bangladesh, e jovens crianças participaram do desenho e do desenvolvimento do projeto, com o fim de garantir que se levasse precisamente em conta suas perspectivas, as quais, literalmente, são uma visão de baixo (Howarth, 1997). Os jovens pesquisadores usaram métodos qualitati- 
As crianças como pesquisadoras: os efeitos dos direitos de participação...

vos e quantitativos, com grupos específicos (focus groups), uma auditoria de prestação de jogos, entrevistas com 83 crianças entre 8 e 12 anos, e com pais, diretores de escolas e trabalhadores comunitários. Descobriram por que tão poucas crianças usavam instalações públicas de recreação e recomendaram como torná-las mais seguras e atraentes.

Num outro projeto comunitário, crianças entre 3 e 8 anos usaram câmeras e fizeram pesquisas de campo e entrevistas a respeito das visões das crianças sobre como melhorar seus conjuntos habitacionais. Publicaram um relatório ilustrado, que seis deles apresentaram e discutiram com autoridades locais num "verdadeiro" encontro em torno de uma mesa. Algumas de suas recomendações foram seguidas, como instalar o pátio de recreio no meio do conjunto, e não de lado nem do lado de estradas periféricas com muito trânsito, como os adultos haviam planejado (Miller, 1997).

Os jovens também ajudam a espalhar as pesquisas de maneira memorável. Em 1994, assisti a sete adolescentes apresentarem relatos e poesias para mais de 200 profissionais da saúde. Primeiro, pediram que o público tapasse os ouvidos com as mãos. Isso durou mais ou menos um minuto, mas pareceu demorar muito mais. Os sorrisos dos participantes começaram a se transformar em perplexidade. Finalmente, um dele disse: "Agora, podem tirar as mãos. Vocês nos perguntam como é, para nós, falar com trabalhadores da saúde. Normalmente, é assim”. Outro exemplo da teatralidade e do imediatismo que as apresentações de jovens podem apresentar ocorreu numa conferência de Barnardo, ${ }^{4}$ quando do lançamento do relatório de pesquisa sobre "Escutar as Crianças" [Listening to Children] (Alderson, 1995). Cinco adolescentes, completamente vestidos de preto, apresentaram uma peça curta em que misturavam a história de Hansel e Gretel ${ }^{*}$ com técnicas de mímica francesa num retrato sombrio e pungente do desespero das crianças quando não eram ouvidas. Embora eu tivesse escrito o relatório e apresentado uma palestra durante a conferência, todo o meu nervosismo se concentrara sobre os atores. Iam mesmo conseguir se apresentar? O que iam fazer? Seria um tremendo fracasso? Iríamos machucar os jovens, e estragar o recado que passamos durante o dia inteiro, ao confiar-lhes tantas responsabilidades? É arriscado pedir que jovens inexperientes e

* N. do T.: História parecida com a de João e Maria. 
que, tradicionalmente, ninguém escuta se apresentem em reuniões públicas assustadoras, oferecendo muito mais que um discurso típico, e é difícil superar nossas ansiedades adultas a este respeito. No evento, a peça conseguiu influenciar os corações e as mentes dos gestores. Depois de uma ovação, o diretor do Barnardo agradeceu-lhes e então abriu o debate para perguntas sobre sessões anteriores. Depois de um longo silêncio, um alto funcionário do Ministério da Saúde disse pensar que todos estavam tão profundamente impressionados pela peça que não conseguiriam falar em outros assuntos.

\section{Níveis de envolvimento das crianças}

A expressão "pesquisas focalizadas em crianças" (child-centred research) abrange, de modo amplo, métodos, estágios ou níveis de envolvimento das crianças (Connolly \& Ennew, 1996). Embora os métodos que envolvem jogos possam parecer bons para crianças, um aspecto crucial é até que ponto os adultos compartilham o conhecimento e o controle com as crianças ou os detêm. Os diferentes níveis de compartilhamento de controle e de participação das crianças já foram comparados, por exemplo, com os degraus de uma escada (Arnstein, 1979; Hart, 1992). Nos níveis mais baixos estão as simulações de trabalho compartilhado: manipulação, papel decorativo e participação simbólica (tokenism). Os níveis seguintes envolvem uma participação real: as crianças recebem tarefas embora sem deixarem de ser informadas e consultadas; e adultos iniciam, mas também compartilham, as decisões com crianças. Os dois níveis superiores dizem respeito a projetos mais plenamente iniciados e dirigidos por crianças.

A imagem da escada pode ser um guia útil para avaliarmos até que ponto as crianças estão ou poderiam estar participando, com tantas barreiras interpessoais e estruturais a serem superadas. Uma das maiores destas é o fato de os financiadores raramente financiarem os estágios iniciais e de acompanhamento da pesquisa, descritos anteriormente como tão importantes para os jovens. Maneiras de envolver as crianças mais plenamente em tomadas de decisóes políticas foram extensivamente relatadas (Lorenzo, 1992; Miller, 1997; Wellard et al., 1997). Contudo, os níveis de participação das crianças também são afetados pela sua própria capacidade de entender questôes relevantes. Jovens crianças podem entender, por exemplo, análise crítica ou políti- 
As crianças como pesquisadoras: os efeitos dos direitos de participação...

cas sobre racismo? Um relatório de uma professora sugere que crianças de 7 anos a quem ela dava aula conseguiriam (Butler, 1998). Ela descreve como as crianças negras do centro de Chicago se conscientizaram das opressóes racial, econômica e política, e como discutiram sua própria experiência de modo intenso em sala de aula. Se alguém quisesse falar de pedras ou de formigas ou de algo não obviamente relacionado com justiça, diriam: "Isso é lindo, mas o que tem a ver com paz e poder?" "Como você vai ajudar teus irmãos e irmãs falando disso?” Elas analisaram as contradiçõoes entre retórica e realidade em suas vidas, as pressões sociais que restringem os atos individuais e o que podem fazer para alcançar justiça social, poder, unidade e mudança comunitária.

\section{Métodos usados pelos jovens pesquisadores}

As crianças que trabalham como pesquisadores usam vários métodos, sozinhas ou em grupos, com ou sem adultos. Elas selecionam assuntos de pesquisa, questões e métodos gerais, decidem questões de pesquisa de campo específicas ou assuntos de entrevista, e selecionam os informadores e os locais de observação. Algumas fazem pesquisas-piloto e revisam seus planos, e planejam a coleta, o cotejamento e a análise dos dados. Depois da análise manual ou por computador, elas escrevem relatórios e divulgam os achados, os quais discutem com os gestores (ver, por exemplo, SCF \& Kirklees, 1996, 1997; Ash et al., 1997; Beresford, 1997; Wellard et al., 1997; PEG, 1998a, 1998b). Os relatórios de pesquisa de grupos de jovens abrangem desde longos relatórios datilografados (West, 1997) a simples pôsteres ou boletins, uma exposição de vídeo ou fotográfica, com relatórios e desenhos feitos pela equipe toda ou por grupos menores (Howarth, 1997; Johnson et al., 1996). Os projetos escolares incluem: a produção de um vídeo e a exposição sobre os equipamentos para deficientes na cidade; pesquisas de campo e propostas de novas medidas de segurança nas estradas construídas. As crianças também foram envolvidas em projetos que vão de melhorar o projeto arquitetônico de um novo hospital para crianças em Derby a trabalhar em medidas contra a pobreza em Greenwich (ver Willow, 1997). Um grupo revisou as políticas multiculturais em sua escola, projetou e apresentou uma política ao conselho estudantil; também planejou sessões de formação em serviço para os diretores e funcionários da escola com um grupo local de relações raciais (CCSE, s/d.). 
Algumas crianças pequenas parecem ser capazes de entender métodos complexos. Por exemplo, Emily Rosa, de 9 anos, projetou um refinado teste aleatório com 21 curandeiros por imposição das mãos, os quais participaram de 280 testes. Eles enfiaram suas mãos em buracos afastados de $30 \mathrm{~cm}$ num anteparo, e Emily tirava cara ou coroa para determinar se manteria suas mãos perto da mão esquerda ou direita deles. A meta era mostrar se os curandeiros tinham consciência dos tipos de campos de energia humana pelos quais alegam curar. As respostas certas haviam de ser bem acima dos $50 \%$ para demonstrar sensibilidade, mas foi apenas de $47 \%$ no primeiro teste e de $41 \%$ no segundo. A mãe de Emily acreditava que os curandeiros participaram porque não se sentiram ameaçados por uma criança, e os peritos apreciaram esta maneira simples e nova de conseguirem provas que lançam muitas dúvidas sobre as afirmações dos curandeiros. Antes, testes complicados, demorados e onerosos comparavam as taxas de cura de pacientes depois de imposiçóes terapêuticas e de tratamentos mais ortodoxos (Rosa, 1989).

Jovens pesquisadores pela Inglaterra afora têm usado materiais dos open colleges ${ }^{*}$ para conduzir projetos ambiciosos. Umas alunas que investigavam os direitos de participação das crianças decidiram entrevistar os diretores dos Serviços Educacionais, Sociais e Recreativos (Education, Social and Leisure Services), altos funcionários, líderes da Câmara Municipal e alguns delegados em seis municipalidades do nordeste da Inglaterra. Gravaram fitas e tomaram notas durante as entrevistas com seus professores e um orientador que, mais tarde, pediu-lhes um relatório. Em pares, dirigiram entrevistas acompanhadas por um pesquisador experiente que as achou "brilhantes" e declarou que não teria sido capaz de conseguir o acesso que elas conseguiram - apenas tiveram uma recusa (Allan Siddall, comunicação pessoal). As moças discutiram os méritos dos métodos qualitativos e quantitativos enquanto analisavam suas entrevistas, e mostraram como o material que colheram comprovava claramente que a retórica das autoridades não correspondia com a realidade. Elas apresentaram seu trabalho (Nevison, 1997), o qual, hoje em dia, influencia políticas locais, num lançamento e em conferências na Inglaterra.

N. do T.: Literalmente, universidade aberta. Os programas de estudos independentes dos open colleges são previstos para pessoas que não têm tempo para freqüentar regularmente os campi e permitem que continuem seus estudos nos horários que querem e fora das salas de aula. 
As crianças como pesquisadoras: os efeitos dos direitos de participação...

Num outro projeto, jovens de 16 anos e outros que abandonaram seus tratamentos investigaram as experiências de jovens que abandonavam seu tratamento em cinco cidades britânicas. Este grupo é principalmente constituído por sem-teto e prisioneiros. Os jovens pesquisadores escolheram os assuntos de pesquisa e as perguntas durante cinco reuniōes em casa, e entrevistaram 80 jovens que abandonaram seu tratamento e 22 trabalhadores sociais. Eles empreenderam uma análise qualitativa completa dos resultados e fizeram recomendaçóes com base neles. Trabalharam na redação e na publicação do relatório e falaram com a mídia. Mais tarde, falaram com autoridades locais a respeito do seu trabalho, e gravaram um vídeo (West, 1997). Outro projeto aliou diferentes equipes com um grupo central de pesquisa, e o uso flexível de perguntas principais em 12 locais de pesquisa. Um coordenador estabeleceu um contato direto entre um pesquisador e dois jovens em cada local, e todos eles compuseram o grupo de pesquisa que assumiu o controle geral sobre os métodos e a redação dos relatórios. Identificaram os temas principais e redigiram 20 questóes por tema. Trabalharam principalmente em escolas, mas também com grupos de refugiados e jovens sem-teto (Kenny \& Cockburn, 1997).

Um outro exemplo de métodos usados por crianças é a análise textual. No Children's Express, ${ }^{5}$ os repórteres, de 8 a 13 anos, fazem entrevistas pungentes, e os editores têm entre 14 e 18 anos. Em sua maioria, provêm de meios que lhes oferecem poucas oportunidades, e seus relatórios são publicados em muitos jornais e revistas. Recentemente, 27 deles monitoraram 400 histórias na imprensa britânica e mostraram que cada artigo estereotipava as crianças - como vítimas, bonitinhas, diabinhos, excepcionalmente brilhantes, corrompidas, acessórios para os adultos ou "anjinhos corajosos". Em 1998, organizaram uma conferência, Kids these days (As crianças de hoje), para tornar suas pesquisas públicas (Neustatter, 1998).

\section{Pesquisa e jogos}

Um aspecto marcante das pesquisas de crianças é que combinam trabalho e jogo. Os jovens pesquisadores recorrem a sessôes de "quebragelo" para se sentir mais confiantes e relaxados, mais desejosos de escutar um ao outro e de arriscar compartilhar idéias com menos medo de serem desconsiderados (Johnson et al., 1996; Treseder, 1997). A Convenção da 
ONU vincula os direitos de ingressar na vida cultural ao direito de brincar (artigo 31), e realça que métodos lúdicos podem melhorar a imaginação de pesquisa das crianças. Por exemplo, brincar de "faz-de-conta" pode envolver crianças jovens no planejamento de melhorias em playgrounds e creches (Miller, 1997). Do mesmo modo, um material alegre e bem ilustrado produzido com crianças mostra como promover participação, negociação e compartilhamento de poder verdadeiros por meio de jogos, com detalhes sobre a promoção de oportunidades iguais e "Métodos de espaço para conversa" (Chat space methods) (sCF e Kirklees, 1996). As abordagens lúdicas ajudam as equipes de pesquisa a gostar tanto de estarem juntas como de trabalharem juntas, e a manter o entusiasmo das crianças que, geralmente, são voluntárias. As crianças pequenas podem ser boas para escutar, questionar, desafiar, não fugir do assunto, e se ajudarem a aprender e desenvolver idéias (McNamara \& Moreton, 1997; O'Kane, 2000). Por exemplo, junto com crianças pequenas os adultos selecionam assuntos e idéias que anotam em palavras ou imagens em grandes folhas e todos têm bolinhas de cores para colar do lado dos itens de que mais gostam. Isso proporciona uma avaliação instantânea relativamente anônima e que todos podem ver numa olhada só. É uma entre tantas maneiras democráticas, rápidas e divertidas de avaliar as opiniōes. As crianças muito pequenas ou analfabetas podem contribuir com dados detalhados por intermédio de seus sonhos e músicas, por meio de modelos, desenhos ou mapas sobre sua mobilidade e as rotinas cotidianas (Johnson et al., 1996; Boyden \& Ennew, 1997) ou sobre a vida selvagem local (Hart, 1997).

\section{Pesquisa e trabalho}

Já disseram que o trabalho das crianças reflete o trabalho dos adultos, por ser principalmente quer físico, quer mental (Qvortrup, 1998). As sociedades européias e norte-americanas tendem a identificar o trabalho, e portanto a pesquisa, com o esforço mental. Em culturas que enfatizam mais o trabalho físico, os dois exemplos seguintes poderiam ser vistos como pesquisa-ação, uma vez que o conhecimento é adquirido por meio de várias etapas diferentes: aprender a partir das dificuldades, planejar os projetos, coletar e aplicar novos conhecimentos, tornar públicos os produtos de pesquisa (respectivamente comida e notícias) e testar as respostas do público. Primeiro exemplo: durante suas reuniões men- 
As crianças como pesquisadoras: os efeitos dos direitos de participação...

sais, garotos de rua de Nova Delhi perceberam que gastavam 75\% de seu dinheiro em comida e planejaram seu projeto. Doze rapazes de 7 a 17 anos fizeram um curso intensivo de dez dias sobre culinária, nutrição, limpeza, atendimento ao cliente e contabilidade, e receberam uma ajuda para alugar um espaço a fim de abrir um restaurante. No começo, aceitaram meio salário dizendo: "Não podemos esperar fazer sucesso da noite para o dia neste negócio, temos de agüentar as perdas por um tempo... e trabalhar duro". Deram comida de graça a algumas crianças de rua, aprenderam culinária chinesa para expandir seu cardápio e planejaram guardar dinheiro para comprar uma caminhonete para levar comida até uma área onde há muitas crianças de rua, financiados pela venda de lanches em lugares públicos (ISCA, 1995, p. 239). Segundo exemplo: em 1993, em Sarajevo, 18 editores entre 10 e 13 anos dirigiram um programa de rádio, chamado "Parede Colorida", com uma audiência estimada em $80 \%$ de todos os cidadãos locais. Fizeram pesquisas sobre as visões das crianças e consideraram o planejamento de seus programas nos resultados. Quinze centros de imprensa foram espalhados pela cidade, nos quais as crianças levavam notícias que também podiam ser comunicadas por telefone, quando este estava funcionando. Naquela época, muitas escolas estavam fechadas e muitas crianças estavam feridas ou enlutadas. O programa incluía educação, diversão e apoio psicológico para elas, com conselheiros, mensagens pessoais e um horário cotidiano sobre os direitos da criança. Os jovens radialistas tornaram-se especialmente populares e, como os rapazes de Nova Delhi, foram entusiastas na avaliação e na expansão de seu trabalho.

\section{Problemas práticos para as crianças pesquisadoras}

Entretanto, vários problemas e questões surgem para as crianças pesquisadoras, assim como acontece com pesquisadores adultos "leigos" (Pratt \& Loizos, 1992) e para crianças que são sujeitos de pesquisa (Alderson, 1995). Como jovens pesquisadores podem trabalhar com adultos em termos razoavelmente iguais, informados e livres de pressão? Quanta responsabilidade é justo esperar que as crianças assumam e até que ponto os adultos deveriam intervir para apoiá-las ou controlar a pesquisa? Como os adultos podem evitar explorar ou manipular as crianças, como nas escadas de participação mencionadas anteriormente? Quanto tempo as crianças deveriam dedicar à pesquisa além dos 
trabalhos ou estudos que também podem realizar na escola, em casa ou não, ou pedindo esmola? Deveriam ser pagas? Em caso afirmativo, quanto, e em dinheiro ou em espécie? Pode haver mais problemas com despesas de pesquisa, e acesso a reunióes de pesquisa para crianças que precisam ser acompanhadas por um adulto. Quando a pesquisa passa pela escola, os professores podem precisar ser, ou insistirem em ser, envolvidos e isso pode criar novos desequilíbrios de poder entre adultos e crianças que deverão ser resolvidos. Quando crianças pesquisadoras parecem estar impressionadas demais, por exemplo com as visões coletadas das autoridades, os adultos deveriam encorajá-las a serem mais críticas? E quem deveria ter o controle final sobre os dados e relatórios: as crianças, os adultos ou todos em conjunto?

Os jornalistas, por exemplo, podem ter mais vontade de tornar públicas as pesquisas de crianças, mas também podem distorcê-las, assim como acontece com algumas pesquisas de adultos. Uma escola primária foi louvada pelo Guardian ${ }^{6}$ pelas suas inovações conquistadas com dificuldade (Highfield School, 1997), mas estas foram depreciadas pelo jornal local. Quando as crianças se queixaram ao editor, este se negou a responder. Então, cada criança da escola escreveu uma carta que mandou por fax. Depois de ver seu fax lotado por várias horas, acabou aceitando dar-lhes o seu direito de resposta pública. O diretor acreditava que elas estavam exercendo seus direitos democráticos como cidadãos.

Mencionei apenas algumas poucas complicações potenciais para mostrar que trabalhar com crianças pesquisadoras não resolve simplesmente problemas de poder, exploração ou coerção. Realmente, também pode aumentá-los, motivo pelo qual os métodos de trabalho devem ser planejados, testados, avaliados e desenvolvidos com os jovens pesquisadores. Uma vantagem de trabalhar em uma equipe de pesquisa com elas é que há mais tempo para conversar do que pode haver com a criança sujeito da pesquisa, assim como para transformar os problemas em oportunidades para que crianças e adultos aumentem seus conhecimentos e habilidades.

\section{Conclusão: trabalhar com crianças pesquisadoras}

A crescente literatura sobre crianças como pesquisadores sugere que elas são um recurso subestimado e subutilizado. Assim como as pesquisas sobre mulheres se tornaram muito mais penetrantes quando pas- 
As crianças como pesquisadoras: os efeitos dos direitos de participação...

saram a envolvê-las como pesquisadoras, a abrangência das pesquisas sobre crianças poderia ser ampliada pelo seu envolvimento como pesquisadoras em muitos métodos, níveis e estágios do processo. As crianças são a fonte primária de conhecimento sobre suas próprias visões e experiências. Elas podem ser um meio de acesso a outras crianças, inclusive às que podem ser protegidas de adultos "estranhos". A originalidade e o imediatismo dos relatórios de pesquisas de crianças podem atrair mais publicidade e interesse em se utilizar seus achados do que muitas pesquisas de adultos. Fazer pesquisa ajuda as crianças (talvez mais particularmente as crianças carentes) a ganhar mais habilidades, confiança e até determinação para superarem suas desvantagens do que os pesquisadores adultos trabalhando em seu nome poderiam lhes oferecer. Os pesquisadores adultos têm registrado sua surpresa diante da competência de pesquisa das crianças, e estão planejando fazer trabalhos mais complicados e trabalhar com crianças menores no futuro. Os pesquisadores adultos costumam enfatizar como é valioso escutar as crianças, e isso acontece de modo muito mais efetivo quando as crianças podem expressar-se ao fazer e relatar publicamente suas próprias pesquisas.

Hoje, novas pressóes políticas e financeiras promovem a pesquisa pelas crianças. As ONGs seguem a orientação internacional de que seus próprios serviços e pesquisas devem "focalizar as crianças", e serem forte e diretamente influenciados por crianças, de acordo com a Convenção da ONU de 1989. Os governos que ratificaram essa Convenção também devem fazer a mesma coisa em todos os seus órgãos. À medida que mais pesquisas de crianças são publicadas, os perigos de se ignorar suas visões (Cooter, 1992) e os benefícios de trabalhar com elas tornam-se mais óbvios. Agências de financiamento como o Economic and Social Research Council (ESRC) e a Rowntree $^{8}$ esperam que os pesquisadores trabalhem estreitamente com os grupos de usuários, do começo até os estágios de implementação das pesquisas. Embora isso apresente desvantagens potenciais, quando poderosas associaçóes comerciais ou profissionais impedem os pesquisadores de serem ousados, independentes e críticos, consultar as crianças como o maior "grupo de usuários" das pesquisas que as afetam pode diminuir os desequilíbrios de poder intergeracionais. Nossos exemplos mostram que trabalhar com jovens pesquisadores pode originar novas direçōes de pesquisa, sem deixar de respeitar os direitos da criança.

Um folheto para jovens "cujo sentido de aventura e idealismo é a única esperança para uma ação mais voluntária no futuro contra atos vis 
que prejudicam o ser humano e a Natureza" cita Gandhi: "Minha humilde tarefa foi mostrar às pessoas como podem resolver suas próprias dificuldades" (Oza, 1991). As ONGs trabalham com crianças pesquisadoras para melhorar a compreensão das vidas das crianças, de seus interesses, suas preocupações, capacidades e necessidades; para vê-las no contexto de sua família, comunidade e sociedade; para demonstrar a sua habilidade em tomar parte em pesquisas, suas competências, ingenuidade e originalidade. Elas mostram como as crianças podem ter perspectivas únicas e válidas para informar as políticas sociais (SCF, 1997, p. 2-5) e ajudá-las a resolver suas próprias dificuldades.

Finalmente, a moda de excluir pesquisadores pessoalmente afetados pelo assunto de pesquisa, de medo que se mostrem tendenciosos, tem sido amplamente superada pelo respeito por pesquisadores com conhecimento de dentro. Todos os argumentos propostos por pesquisadores negros ou feministas para defender suas pesquisas a respeito de seus próprios grupos também se aplicam às crianças. A desconstrução pós-moderna da subjetividade vê isso

como um produto de poder do que como seu autor; e [vê] a ação como uma maneira de o poder agir por intermédio do indivíduo... [O poder] não é unitário nem sem ganhadores e perdedores (zero-sum), mas difuso, plural e em mudança perpétua... Na realidade, os eus que achamos serem fixos e unitários são instáveis, fragmentados e contraditórios. Assim, [o pósmodernismo] pode potencialmente nos ajudar a olhar para as mudanças e as tensōes (tal como a de opressor-oprimido) em quem nós mesmos acreditamos ser... O ato de desconstrução é político, pois expõe as intricadas operações de poder que constituem a subjetividade. (Aziz, 1997)

Em pesquisas sobre crianças, a questão-chave é: como os adultos podem ir além dos limites de poder e expor as complexidades do poder nas relações entre adultos e crianças? As pesquisas por crianças, com seu enfoque do poder antes, durante e depois dos estágios de pesquisa formal, com seu recurso a jogos com um potencial parcialmente subversivo, e sua expansão além do pensamento num fazer compartilhado, podem oferecer abordagens úteis. Quando entrevisto pessoas deficientes ou negras, acho que, embora discutamos dificuldades que surgem da discriminação, também estamos parcialmente dissimulando nossas diferenças para tentar manter relações iguais e respeitosas. Em contraste, quando pesquisadores negros falam com entrevistados negros, suas experiências comuns dessas diferenças lhes permitem explorá-las muito 
As crianças como pesquisadoras: os efeitos dos direitos de participação...

mais profundamente (Scott, 1998) e essa exploração compartilhada pode se aplicar às pesquisas de crianças sobre crianças.

As noções de infância variam e não é fácil transferir experiências, estruturas e atitudes entre culturas. Nos países pobres e devastados por guerras, as crianças pesquisadoras tendem a se envolver de modo mais ousado tanto em trabalhos de adultos como em pesquisas; elas não podem montar restaurantes no Reino Unido tão simplesmente como em Nova Delhi. Portanto, as limitações das pesquisas de crianças, na Europa e na América do Norte, parecem dever-se menos às (in)competências das crianças que às atitudes limitantes dos adultos, a coerções e preocupações com a sua proteção, a despeito dos direitos de participação. Contudo, as provas de atividades e conquistas das crianças pesquisadoras, assim como seus resultados de pesquisa, vão provavelmente promover apreciações mais respeitosas e realistas sobre suas habilidades como atores sociais.

\section{Recebido em novembro de 2004 e aprovado em março de 2005.}

\section{Notas}

1. Associação Britânica de Pesquisa em Educação. Disponível em: <http://www.bera.ac.uk>.

2. A Child-to-Child Trust é uma organização ligada ao Instituto de Educação e Saúde da Criança da University of London. Seu objetivo central é proteger e preservar a saúde de comunidades ao redor do mundo, encorajando crianças e jovens a desempenharem um papel ativo e responsável na saúde e no desenvolvimento deles próprios e de outras crianças, e de suas famílias. Disponível em: <http://www.child-to-child.org>.

3. Traduzido para o português como Grupo de Participação e Educação.

4. A organização Barnardo foi fundada em 1845 e atualmente trabalha com crianças e jovens em situação de risco. Sua função é ajudá-los a transformar suas vidas e desenvolver seus potenciais. Hoje em dia, 100.000 crianças e suas famílias são ajudadas por intermédio de 361 serviços na Inglaterra, Irlanda do Norte, Escócia e no País de Gales. Disponível em: $<$ http://www.barnardos.org.uk>.

5. Children's Express é uma agência de notícias inglesa, de responsabilidade de crianças e jovens com idades entre 8 e 18 anos. Pela aprendizagem por meio de um programa jornalístico, crianças e jovens pesquisam e escrevem histórias, que são importantes para elas, para serem publicadas em jornais e revistas nacionais e locais. Disponível em: <http:/ /www.childrens-express.org>.

6. Um dos principais jornais da Inglaterra. Disponível em: <http://www.guardian.co.uk>.

7. Financia pesquisas e treinamentos nas áreas econômica e social. Disponível em: <http:// www.esrcsocietytoday.ac.uk>.

8. Agência de financiamento de pesquisa. Disponível em: <http://www.jrf.org.uk/funding/ research>. 
Referências bibliográficas

ALDERSON, P. Children's consent to surgery. Buckingham: Open University Press, 1993.

ALDERSON, P. Listening to children: ethics and social research. Barkingside: Barnardo's, 1995.

ALDERSON, P. Consulting children aged from birth to eight years: a report for Save the Children. London: SCF, 1999.

ALDERSON, P.; GOODEY, C Enabling education: experiences in special and ordinary schools. London: Tufnell Press, 1998.

ALDERSON, P.; GOODWIN, M. Contradictions within concepts of children's competence. International Journal of Children's Rights, 1, 3/4, p. 303-312, 1993.

ALDERSON, P.; MONTGOMERY, J. Health care choices: making decisions with children. London: Institute for Public Policy Research, 1996.

ARNSTEIN, S. Eight rungs on the ladder of citizen participation. Journal of the American Institute of Planners. Adapted by Hart, R. Children's participation: from tokenism to citizenship, 1992. UNICEF Innocent essays, 1979.

ASH, A.; BELLEW, J.; DAVIES, M.; NEWMAN, T.; RICHARDSON, L. Everybody in? The experience of disabled students in further education. Disability and Society, 12, 4, p. 605-621, 1997.

BERA, British Education Research Association. Ethical guidelines for educational research. Slough: BERA, 1992.

BERESFORD, B. Personal accounts: involving disabled children in research. York, SPRU. Boyden, J.; Ennew, J. Children in focus; a manual for participatory research with children. Stockholm: Radda Barnen, 1997.

BUTler, M. Negotiating place. In: Steinberg, S.; Kincheloe, J. (Ed.). Students as researchers. London: Falmer, 1998. p. 94-112.

CCSE. Citizenship Education, n. 31, Leicester: Centre for Citizenship Studies in Education. (s./d.) 
As crianças como pesquisadoras: os efeitos dos direitos de participação...

COCKBURN, T.; KENNY, S; WEBB, M. Moss side youth audit: phase 2, indicative findings in employment and training. Manchester: Manchester City Council and Manchester Metropolitan University, 1997.

CONNOLLY, M.; ENNEW, J. (Ed.). Children out of place: special issue on working and street children. Childhood, 3, 2, 1996.

COOTER, R. In the name of the child. London: Routledge, 1992.

GARDNER, H. The unschooled mind. New York: Fontana, 1993.

HART, R. Children's participation. London: Earthscan/UnICEF, 1997. p. 98.

HIGHFIELD SCHOOL (Ed. P. Alderson). Changing our school. Plymouth: Highfield School/London: Institute of Education, 1997.

HOWARTH, R. 'If we don't play now, when can we?. London: Hopscotch Asian Women's Centre, 1997.

HUTCHBY, I.; MORAN-ELLIS, J. (Ed.). Children and social competence: arenas of action. London: Falmer, 1998.

ISCA, International Save the Children Alliance. UN Convention on the Rights of the Child training kit. London: SCF, 1995.

JAMES, A.; PROUT, A. (Ed.). Introduction: Constructing and reconstructing childhood. London: Falmer Press, 1997.

JOHNSON, V.; HILL, J.; IVAN-SMITH, E. Listening to smaller voices: children in an environment of change. Chard: Action Aid, 1996.

KENDRICK, C. et al. Children's understanding of their illness and treatment within a paediatric oncology unit. ACPP Newsletter, 8, 2, p. 16-20, 1986.

KENNY, S.; COCKBURN, T. Moss side youth audit: final report. Manchester: Manchester City Council and Manchester Metropolitan University, 1997.

LIPMAN, M. (Ed.). Thinking children and education. Dubuque, Iowa: Kendall/Hunt, 1993.

LORENZO, R. Italy: too little time and space for childhood. Florence: UNICEF Innocent studies, 1992. 
MCNAMARA, S.; MORETON, G. Understanding differentiation: a teachers guide. London: David Fulton, 1997.

MILLER, J. Never too young. London: National Early Years Network/Save the Children, 1996.

NEUSTATTER, A. Kids - what the papers say. The Guardian, 8 mar. 1998.

NEVISON, C. A matter of opinion. London: Save the Children, 1997.

OZA, D. Voluntary action and Gandhian approach. New Delhi: National Book Trust India, 1991.

PEG. Schools can seriously damage your health: how children think school affects and deals with their health. Gateshead: PEG, 1998a.

PEG. PEG Newsletter, Celebration Issue. Gateshead: PEG, 1998b.

PRATT, B.; LOIZOS, P. Choosing research methods: data collection for development workers. Oxford: Oxfam, 1992.

QVORTRUP, J. et al. Childhood matters: social theory, practice and politics. Aldershot: Avebury, 1994.

QVORTRUP, J. Plenary lecture to conference on Childhood and social exclusion. Hull: Centre for the Social Study of Childhood, 1998.

ROBERTS, H.; SMITH, S.; BRYCE, C. Children at risk? Safety as a social value. Buckingham: Open University Press, 1995. p. 34.

ROSA, E. Journal of the American Medical Association, n. 279, p. 1005-1010, 1989.

SAVE THE CHILDREN. Towards a children's agenda. London: SCF, 1995.

SAVE THE CHILDREN; KIRKLEES METROPOLITAN COUNCIL. The children's participation pack: a practical guide for play workers. London: SCF, 1996.

SAVE THE CHILDREN. Learning from experience: participatory approaches in Save the Children. London: SCF, p. 2-5, nov. 1997.

SCOTT, P. Caribbean people's experience of diabetes. In: Hood, S.; Mayall, B.; Oliver, S. (Ed.). Critical issues in social research: power and prejudice. Buckingham: Open University Press, 1998. 
As crianças como pesquisadoras: os efeitos dos direitos de participação...

SOlBERG, A. Negotiating childhood. In: James, A.; Prout, A. (Ed.). Constructing and reconstructing childhood. London: Falmer, 1997.

SPENCER, S. The implications of the Human Rights Act for education. Keynote address to the fifth international summer school of the Education in Human Rights Network, Birmingham, 1998.

TIZZARD, B.; HUGHES, M. Young children learning. Glasgow: Fontana, 1984.

TRESEDER, P. Empowering children and young people: a training manual for promoting involvement in decision-making. London: SCF and CRO, 1997.

UNITED NATIONS. Convention on the Rights of the Child. Genebra: ONU, 1989.

WELLARD, S.; TEARSE, M.; WEST, A. All together now: community participation for children and young people. London: SCF, 1997.

WEST, A. Learning about leaving care through research by young care leavers. In: Learning from experience: participatory approaches in SCF. London: Save the Children, 1997.

WILKINSON, S. The child's world of illness: the development of health and illness behaviour. Cambridge: Cambridge University Press, 1988.

WILLOW, C. Hear! Hear! Promoting children's and young people's democratic participation in local government. London: Local Government Information Unit, 1997. 